\title{
COMPARATIVO DA UTILIZAÇÃO DE MAPAS MENTAIS EM DOIS CENÁRIOS: DESENVOLVIMENTO DE PRODUTOS USANDO "DESIGN THINKING" E DESENVOLVIMENTO DE SOLUÇÕES USANDO IOT
}

Renato Vizioli (renato.vizioli@gmail.com) - Faculdade de Arquitetura e Urbanismo / Design / Universidade Presbiteriana Mackenzie

Paulo Carlos Kaminski (pckamins@usp.br) - Departamento de Engenharia Mecânica / Escola Politécnica / Universidade de São Paulo

Victor Alexandre Cândido Athanasio (victorathanasio@usp.br) - Departamento de Engenharia Mecatrônica e de Sistemas Mecânicos / Escola Politécnica / Universidade de São Paulo

\section{RESUMO}

A utilização do mapa mental tem sido feita em inúmeras situações, sempre procurando ampliar escopos, ilustrar contextos, facilitar o entendimento de problemas, mas, principalmente, para mostrar oportunidades e caminhos para a busca de soluções, o que, de modo geral, adéqua-se bem ao desafio do desenvolvimento de produtos e serviços. Desta forma, o desenvolvimento de soluções IoT, que agregam produtos, serviços e sistemas integrados com alto grau de análise de dados e tomada de decisão, também se enquadram no rol dos desafios que demandam inúmeras ferramentas de desenvolvimento, dentre as quais, o mapa mental. Neste trabalho, foi feita uma análise comparativa de diversos mapas mentais elaborados em contextos de produtos e serviços sem e com IoT, partindo de uma premissa de que no desenho do mapa para o caso do IoT deveria haver uma camada adjacente à ideia central, cujo teor fosse abstrato ou de valores de pouca tangibilidade ou materialidade. A análise comparativa e o confronto com as soluções propostas, mostrou que, quanto mais os grupos aderiram a esta premissa, maior foi o grau de exploração do problema e mais variadas foram a oportunidades prospectadas.

Palavras chave: Mapa mental; Internet das coisas; Desenvolvimento de produtos 


\section{INTRODUÇÃ̃}

O uso da ferramenta do mapa mental, formalizado somente nos anos 1990 (BUZAN e BUZAN, 1994), tem se mostrado bastante abrangente, incluindo inúmeras aplicações em áreas de negócio (desenvolvimento de produtos, resolução de problemas, etc.), ensino e pesquisa (infográficos, organização de ideias, etc.).

Dentro da abordagem do "design thinking", (VIANNA et al., 2012), é comum verificar-se a sua utilização, ao longo do desenvolvimento dos conceitos, principalmente nas fases iniciais, quando o problema é demasiado vago, e, o mapa mental mostra-se robusto na ampliação das percepções de oportunidades e de possíveis caminhos para propor soluções.

Ainda no "design thinking", o mapa mental, bem como o mapa conceitual - variação com caráter hierárquico e classificatório - são fundamentais na estruturação da ideia (BROWN, 2010), pois refletem construções mentais, não só de um indivíduo, mas de uma coletividade, quase sempre confrontando antagonismos buscando convergir a um consenso. Segundo Brown (2010), o pensamento linear é aquele associado ao mapa conceitual, relacionado às sequências, enquanto que os mapas mentais se referem a conexões, ou seja, ligações semânticas. O uso do "design thinking" no desenvolvimento de produtos e serviços tem sido frequente, e, pode se dar de forma completa, ou apenas de algumas de suas ferramentas, e, inserido num contexto com outras metodologias e processos, como, por exemplo, o PDP (processo de desenvolvimento de produtos) e a engenharia e análise do valor (VIZIOLI, 2019).

Já o IoT - Internet das coisas - é um termo que surgiu da consolidação sistêmica de soluções que envolvem produtos e serviços, em um ambiente integrado de dados com "inteligência" para tomada de decisão autônoma. Segundo Porter e Heppelmann (2015), IoT pode ser descrita como produtos inteligentes e conectados, abrangendo um universo de aplicações que vai de roupas e utensílios domésticos até cidades e equipamentos industriais, compartilhando três elementos centrais: componentes físicos ("coisas"), componentes com inteligência embarcada (sensores, micro processadores, controladores, aplicativos, dados armazenados e interfaces com os usuários, etc.) e componentes de conectividade (protocolos de comunicação, redes sem fio, antenas, etc.).

Deste modo, soluções que envolvem IoT, agregam uma maior complexidade, tendo em vista que, às tradicionais conexões com os participantes do processo, como o usuário, o fabricante do produto, o provedor do serviço, os diversos fornecedores, os órgãos reguladores, etc., são acrescidas conexões que utilizam o que se convenciona chamar de "nuvem", em um ambiente 
de dados em volumes que caracterizam um "big data", e, processam informações utilizando técnica analíticas refinadas e, muitas vezes, lançando mão do uso da "inteligência artificial" (MARJANI et al., 2017).

Considerando-se esta diferença de complexidade, foi levantada a questão de como se utilizar ferramentas corriqueiramente aplicadas no desenvolvimento de produtos convencionais (sem IoT), em um cenário utilizando IoT, e, como ponto de partida, buscou-se analisar o uso do mapa mental.

Contemplando este maior grau de abstração, foi proposta a introdução no mapa mental - no caso do desenvolvimento de soluções IoT - de uma camada imediatamente após a ideia central, contendo relações semânticas de valor, ou seja, evitando-se buscar uma materialização dos conceitos semânticos num primeiro momento, como será descrito posteriormente.

Para se ter um volume razoável de informações comparativas, foram aplicadas dinâmicas em sala de aula em um programa de MBA, em duas disciplinas distinta, a primeira delas focada em desenvolvimento de produtos e serviços utilizando "design thinking", e a segunda, focada em soluções utilizando IoT.

Pretendeu-se, então, verificar a aderência dos propósitos da ferramenta aos dois cenários: desenvolvimentos sem e com IoT, através de uma avaliação do grau de clareza dos mapas gerados e da percepção dos vínculos do conteúdo dos mapas com a solução final proposta.

\section{UTILIZAÇÃO DO MAPA MENTAL ASSOCIADO AO "DESIGN THINKING"}

Mapear informações complexas de forma visual é um processo de busca de padrões que extrai significado através de revisões na literatura, nas observações e em entrevistas (TSCHIMMEL, 2012). A possibilidade de organizar visualmente informações coletadas sobre determinado projeto não apenas ajuda na comunicação interna do grupo envolvido com o projeto, mas também provoca novos "insights" sobre o projeto, uma vez que cada interpretação visual de uma informação coletada se constitui numa síntese e impulsiona novas reflexões. Tschimmel (2012) exemplifica vários tipos de mapas ou representações visuais de informações coletadas e organizadas, como mapas de afinidade ou de empatia, mapas de expectativas, mapas de processos e mapas que representam a jornada do usuário.

Tony Buzan e Barry Buzan (BUZAN e BUZAN, 1994) propuseram o mapa mental como uma ferramenta que une características verbais e visuais. Para eles, a ferramenta simula a forma 
como o hemisfério esquerdo do cérebro organiza e armazena as informações, de modo radial e causal, ampliando conceitos a partir de algumas ideias centrais. Os autores basearam sua proposta, em investigações do professor Roger Sperry feitas nos anos 1960 sobre os hemisférios do cérebro, segundo as quais, o lado direito é responsável por áreas intelectuais como ritmo, percepção espacial, "gestalt" ou visão holística, imaginação, sonhos ou desejos, cores e dimensões. O hemisfério esquerdo, por sua vez, apresenta dominância em aspectos como a expressão verbal, a lógica, matemática, encadeamento e linearidade, listas e análises. Algumas representações de mapas mentais, como visto na Figura 1 são repletas de analogias de modo a tornar o processo próximo a processos fisiológicos.

Figura 1 - Exercício inicial sobre mapas mentais aplicado por Buzan e Buzan

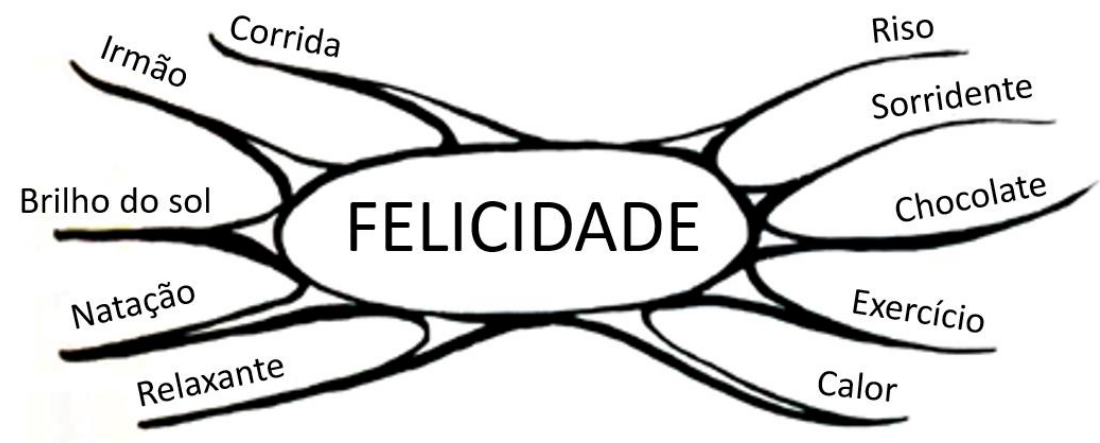

Fonte: traduzido de Buzan e Buzan (1994)

A Figura 1, ilustra a ideia de que no mapa mental, sempre se inicia a partir de um conceito inicial - felicidade, no caso - e vai-se agregando sempre de modo radial e em camadas, ideias associadas às anteriores. Olhando-se mapas com inúmeras camadas, as ideias mais periféricas podem estar aparentemente desvinculadas da ideia central, porém, há um encadeamento que as justificam.

Diferentemente do mapa conceitual (EPPLER e PFISTER, 2014; VIZIOLI e KAMINSKI, 2014; EPPLER, 2016), onde, além de serem mostradas as ideias encadeadas, acrescenta-se conectores, explicando o tipo de relação existente entre as mesmas, o mapa mental procura conexões não hierárquicas. No mapa mental mostrado na Figura 1, as relações causais aparentam ser mais subjetivas, ficando estranho usar o mesmo raciocínio do mapa conceitual. Por exemplo: felicidade gera sorrisos ou felicidade é favorecida por exercícios e assim por diante. O mapa conceitual tende, portanto, a restringir a geração de ideias, mas, por outro lado, 
favorece o entendimento de conceitos. Por exemplo: música altera o comportamento e gera a felicidade, e assim sucessivamente.

Mapas mentais (BUZAN e BUZAN, 1994) são representações gráficas em forma de diagrama radial, expandindo-se a partir de um conceito central que se relaciona semanticamente com outros conceitos, também hierarquicamente. Usualmente é construído com círculos coloridos em aplicativos ou utilizando-se etiquetas autoadesivas (a ideia central tem uma cor e ideias agrupáveis têm cores distintas), ligados por linhas, ou através de desenhos mais elaborados, sendo comuns, concepções mais artísticas em versões mais avançadas do mapa.

\section{METODOLOGIA}

Ao longo de duas disciplinas realizadas no MBA do PECE no programa de Gestão e Engenharia de Produtos e Serviços: Vantagem Competitiva pelo Design (2018) e IoT e o Gerenciamento da Informação (2019), foram aplicadas dinâmicas com grupos de alunos (5 a 6 alunos em cada grupo), contemplando, na primeira delas, os temas: aparelhos de comunicação, eletrodomésticos, peças sanitárias, higiene pessoal e equipamentos de escritórios.

$\mathrm{Na}$ segunda, sobre IoT, foram escolhidos quatro temas, seguindo a tendência expressa pelo documento do BNDES/MCTIC (2017), quatro verticais, ou áreas prioritárias, ressaltadas para os projetos de desenvolvimento de soluções utilizando IoT no Brasil: Cidades inteligentes, saúde, rural (agricultura, reflorestamento e pecuária) e indústrias (indústria 4.0).

Em cada uma das disciplinas, a construção do mapa se deu em momentos específicos, observando os processos adotados nas respectivas ementas, porém, em ambos os casos, isto ocorreu cedo, e, até por isso, decidiu-se analisar esta ferramenta, tendo em vista que seu impacto pode ser percebido ao longo de todo o processo.

Foi solicitado às equipes, após uma contextualização inicial sobre os temas, através de pesquisas utilizando basicamente internet, que construíssem o mapa mental. A construção podia ser feita utilizando um quadro em branco (lousa) ou uma folha de cartolina grande, onde foram dispostos os papéis adesivados. Antes de montar o quadro, foi pedido que cada participante (alunos) pensasse e escrevesse no mínimo 3 (três) adesivos, para que então fosse feito o mapa coletivamente.

No caso dos produtos e serviços com IoT, a segunda disciplina, foi pedido adicionalmente, que se pensasse inicialmente em uma camada (primeiro nível) com uma grau de abstração grande, 
ou seja, valores intangíveis e de difícil materialização, para que então, nos níveis subsequentes, fossem adicionados conceitos que buscassem uma maior materialização. O propósito disso, foi procurar adequar a ferramenta ao caráter de maior abstração e complexidade das soluções que utilizam IoT, mas também verificar o quanto as soluções poderiam ser mais abrangentes e variadas do que no caso da primeira disciplina, onde não havia IoT envolvido.

\section{RESULTADOS E DISCUSSÃO}

Inúmeros mapas foram produzidos, sendo que alguns grupos, em ambas as disciplinas, fizeram versões inicias e, seja por orientações dadas em aula, seja porque o grupo verificou, ao longo do processo, que poderia melhorar o mapa, geraram versões posteriores. Neste trabalho, são mostrados os mapas em suas versões consideradas finais (as que foram entregues ao final do curso), e, selecionou-se 3 mapas da primeira disciplina e 4 da segunda (porque os demais ilustram situações muito parecidas)

Inicialmente foi feita uma classificação dos mapas em termos de "níveis de profundidade" da exploração da ideia, considerando que a ideia central corresponde ao nível 0 (zero), os conceitos semânticos ligados a ela correspondem ao nível 1 (um) e assim sucessivamente.

As figuras de 2 a 4 representam os mapas gerados para o caso de produtos e serviços sem IoT, identificados, respectivamente, como 1-A, 2-A e 3-A.

Figura 2 - Mapa mental do grupo 1-A: tema de aparelhos de comunicação

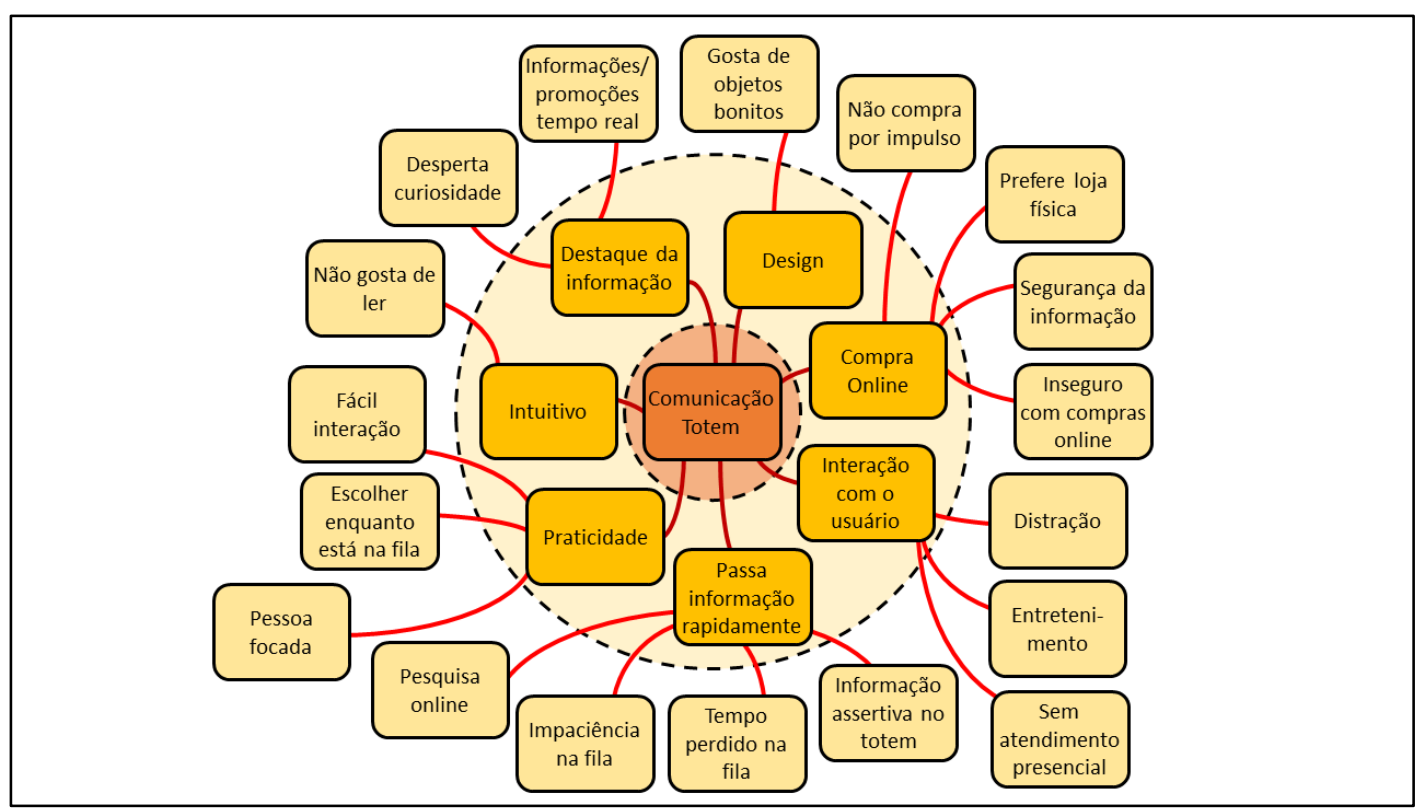


Nota-se que, no mapa da figura 2, o grupo utilizou 2 (duas) camadas, mas, em cada uma delas, procurou expandir os conceitos, colocando 7 (sete) no primeiro nível e 18 (dezoito) no segundo. Nos mapas mostrados nas figuras 3 e 4, foram utilizados mais níveis, porém, com uma exploração menor por nível, algo que, numa primeira abordagem, pode representar um maior aprofundamento, porém com um menor grau de exploração de oportunidades.

Os números levantados nesta classificação são mostrados na tabela 1 .

Também se ressalta que, nos mapas aqui ilustrados (figuras 2 a 8), o leiaute foi refeito para representar melhor os níveis e, também, foram retiradas as duplicidades.

Figura 3 - Mapa mental do grupo 2-A: tema de eletrodomésticos

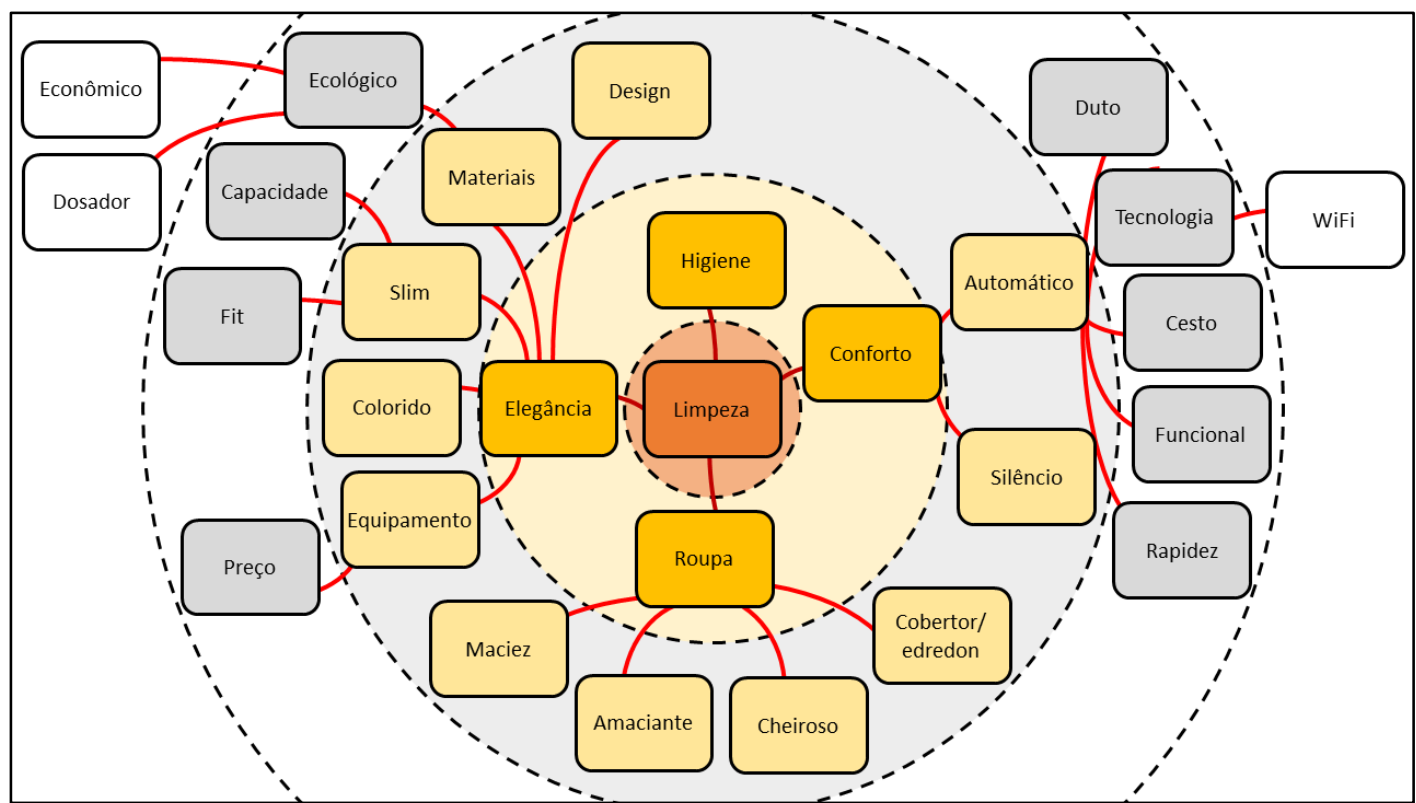


Figura 4 - Mapa mental do grupo 3-A: tema de peças sanitárias

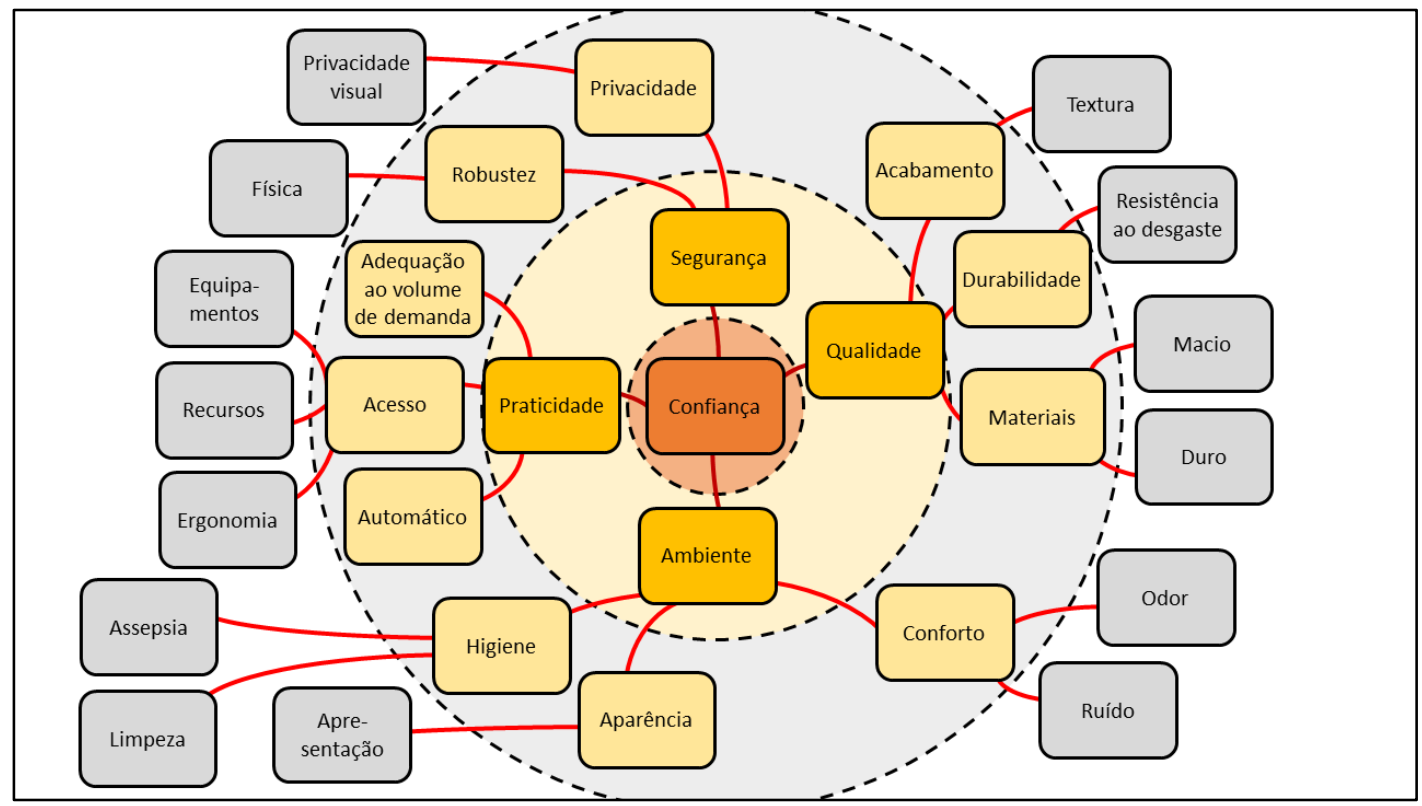

$\mathrm{Na}$ figura 4, as ideias que aparecem no primeiro nível: segurança, qualidade, ambiente e praticidade, já observam o requisito solicitado para a aplicação feita no caso do desenvolvimento de soluções com IoT proposto (mapas das figuras 5 a 8).

Figura 5 - Mapa mental do grupo 1-B: tema rural

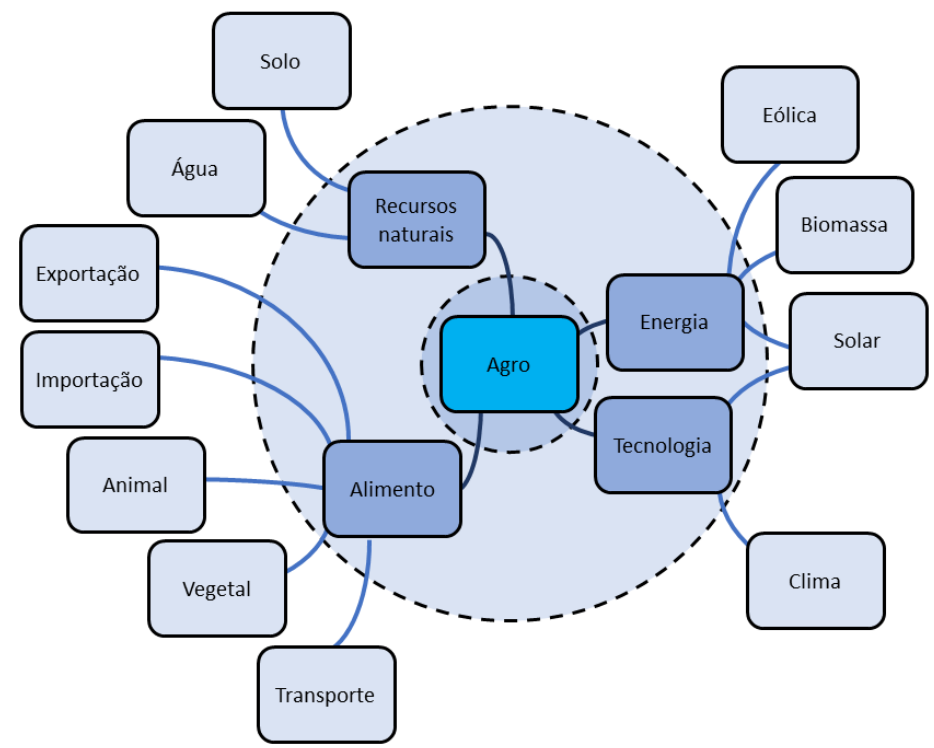

No caso das soluções com IoT, os mapas (figuras 5 a 8), mostram, quase sempre, apenas 2 níveis após a ideia central. Apenas no mapa do tema "saúde" (figura 8), o grupo aprofundou-se 
mais (até o nível 4), porém, em todos os casos, houve menos exploração em termos de número total de ideias, com no máximo 15 conceitos semânticos no caso do tema "agro" (figura 5).

Figura 6 - Mapa mental do grupo 2-B: tema indústria

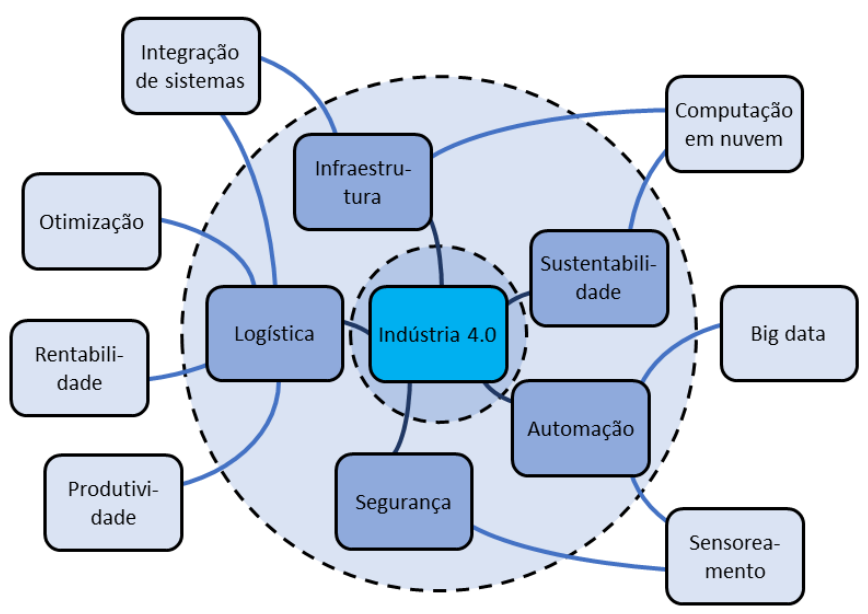

Já o grupo que tratou do tema "cidades inteligentes" do grupo 3-B (figura 7), houve algumas relações compartilhadas entre os níveis 2 e 3, mostrando um maior aprofundamento na identificação das relações.

Figura 7 - Mapa mental do grupo 3-B: tema cidades

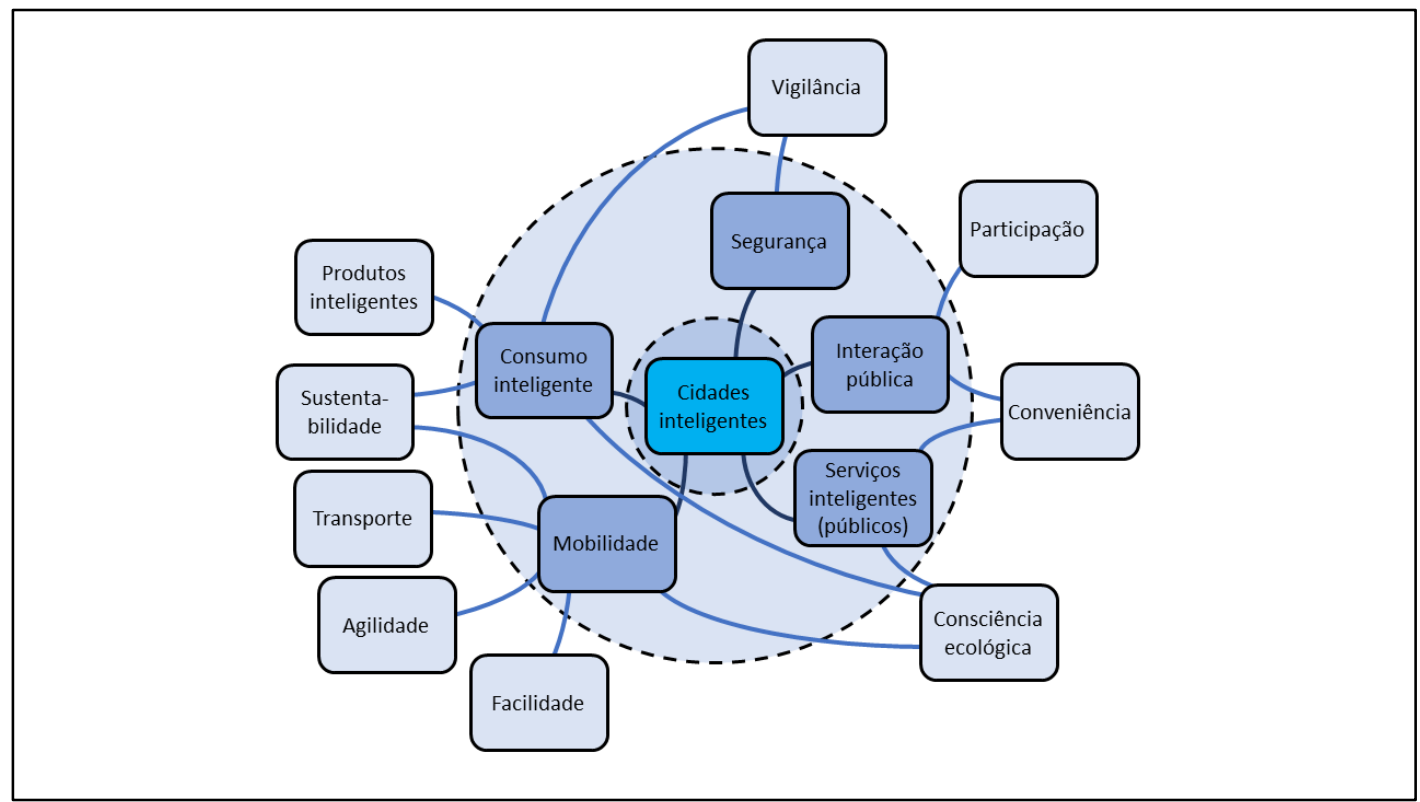

Finalmente, o grupo 4-B responsável pelo tema "saúde" (figura 8), foi até o quarto nível, porém, explorou poucas oportunidades, aprofundando-se em apenas alguns poucos caminhos. 
Figura 8 - Mapa mental do grupo 4-B: tema saúde

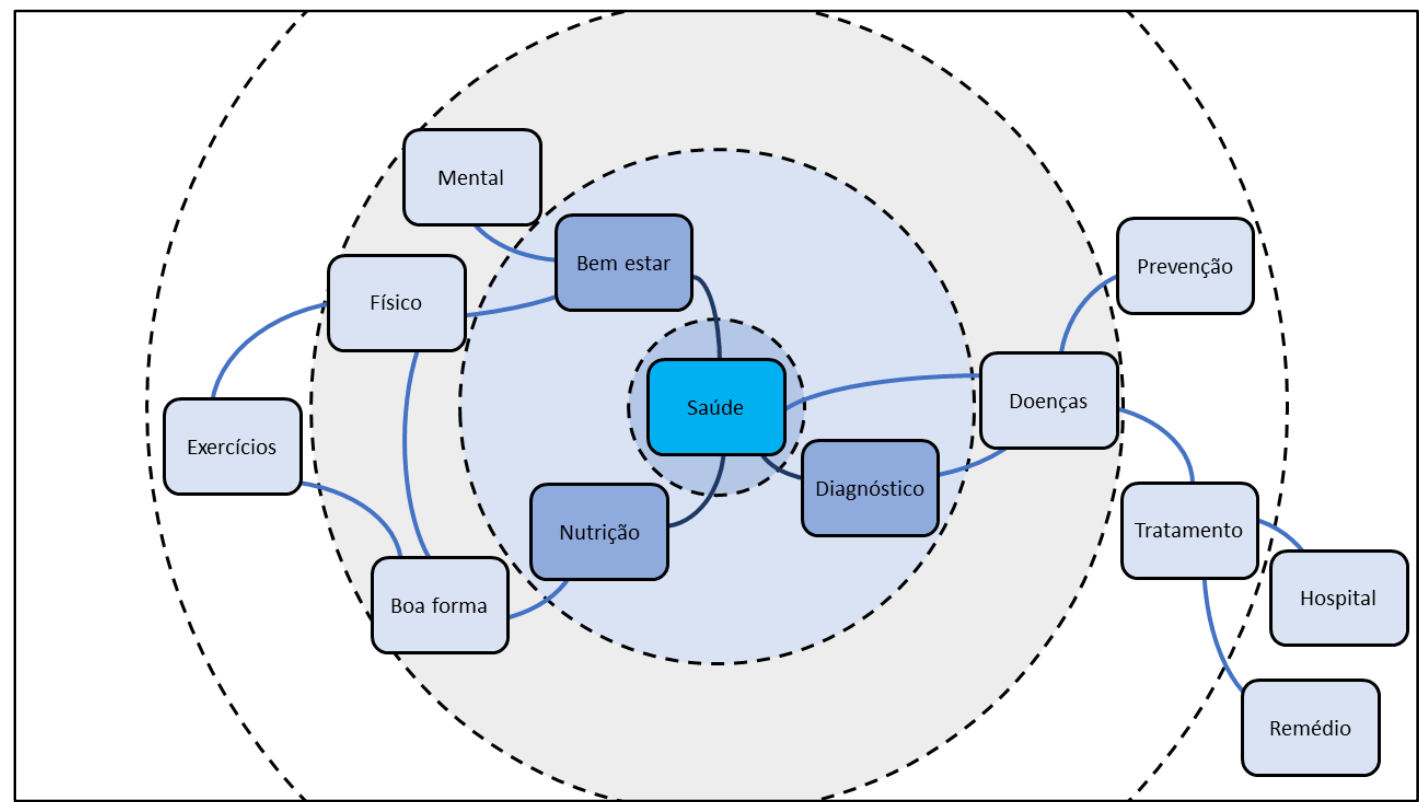

Na tabela 1, são sumarizados os resultados comparativos dos 7 mapas aqui mostrados,

Tabela 1 - Dados comparativos das ideias e dos níveis utilizados

\begin{tabular}{llllllll}
\hline Grupo & $\mathbf{1 - A}$ & $\mathbf{2 - A}$ & $\mathbf{3 - A}$ & $\mathbf{1 - B}$ & $\mathbf{2 - B}$ & $\mathbf{3}-\mathbf{B}$ & $\mathbf{4}-\mathbf{B}$ \\
\hline Níveis & 2 & 4 & 3 & 2 & 2 & 2 & 4 \\
Ideias no $1^{\mathbf{0}}$. nível & 7 & 4 & 4 & 4 & 5 & 5 & 3 \\
Ideias no $2^{\mathbf{0}}$. nível & 18 & 11 & 11 & 11 & 7 & 9 & 4 \\
Ideias no $3^{\mathbf{0}}$. nível & & 9 & 14 & & & & 3 \\
Ideias no 4. nível & & 3 & & & & & 2 \\
\hline Total de ideias & $\mathbf{2 5}$ & $\mathbf{2 7}$ & $\mathbf{2 9}$ & $\mathbf{1 5}$ & $\mathbf{1 2}$ & $\mathbf{1 4}$ & $\mathbf{1 2}$
\end{tabular}

De modo geral, a exploração foi suficiente para embasar as propostas dos grupos, e ficou claro que as soluções foram derivadas dos ramos dos mapas mentais. Conforme mostrado na tabela 2, apenas no mapa 1-A, do grupo que tratou do tema de aparelhos de comunicação, não há, no mapa mental, indícios da solução proposta no final, e, de fato, houve um desvio na construção, a começar pela proposta de ideia central, que já apontava para uma solução pré-definida, no caso, um totem de vendas. 
Tabela 2 - Relação entre temas, conceitos e soluções

\begin{tabular}{|c|c|c|c|}
\hline Mapa & Tema & Conceito oriundo do mapa & Solução proposta \\
\hline 1-A & $\begin{array}{l}\text { Aparelhos de } \\
\text { comunicação }\end{array}$ & Nenhum & Mesa digital para reuniões \\
\hline 2-A & Eletrodoméstico & $\begin{array}{l}\text { Econômico, dosador, dutos, } \\
\text { cesto }\end{array}$ & Máquina de lavar compartimentada \\
\hline 3-A & Peças sanitárias & Higiene, assepsia, limpeza & Tampa de vaso sanitário autolimpante \\
\hline 1-B & Agricultura & Recursos naturais, solo & $\begin{array}{l}\text { Controle de dosagem de nutrientes no } \\
\text { solo }\end{array}$ \\
\hline 2-B & Indústria & Logística & Otimização de logística interna \\
\hline 3-B & $\begin{array}{l}\text { Cidades } \\
\text { inteligentes }\end{array}$ & Mobilidade, transporte & $\begin{array}{l}\text { Otimização de logística de transporte } \\
\text { urbano (modal ônibus) }\end{array}$ \\
\hline 4-B & Saúde & Prevenção, tratamento & $\begin{array}{l}\text { Monitoramento de posição de } \\
\text { pacientes acamados }\end{array}$ \\
\hline
\end{tabular}

Quanto à qualidade das soluções, ainda que o critério de julgamento carregue um certo grau de subjetivismo, pois não foi feito um maior aprofundamento ou teste de mercado, verificou-se que os grupos dos mapas 3-A e 4-B, respectivamente do assento autolimpante e do monitoramento de posição de pacientes acamados, mostraram-se mais funcionais, úteis e inovadores, com soluções mais claras e simples de serem compreendidas.

Em ambos os casos, os grupos exploraram conceitos de valores intangíveis no primeiro nível, e, também, apresentaram 4 níveis de aprofundamento. Paradoxalmente, o grupo de mapa 3-A, foi o que apresentou maior número de conceitos (29), e o 4-B apresentou o menor número (12).

\section{CONCLUSÃO}

Tratou-se de uma exploração, cujas confirmações, para serem mais robustas exigiriam um número de testes maior, porém, pareceu claro, ao longo do processo, que, grupos que fizeram um maior aprofundamento na utilização do mapa mental, preocupando-se em não se fecharem em uma solução predefinida, como fez o grupo do mapa 1-A, tentando montar um mapa mental como que para justificar sua escolha, abriram um leque de opções maior, e puderam definir com mais clareza seus caminhos.

Preliminarmente, pareceu interessante criar a camada de conceitos mais abstratos, senão pelo aspecto da diversificação das soluções, para direcionar os grupos em caminhos cujos valores representassem opções melhores para o grupo.

Outras constatações dizem respeito à relação entre explorações superficiais - com muitos conceitos em poucos níveis - e focadas, aprofundando conceitos em muitos níveis, porém em poucos caminhos. Neste caso, os grupos que souberam equilibrar, ou seja, explorar bem por 
nível e aprofundar suficientemente, tiraram maior proveito da ferramenta, conforme mostraram as soluções propostas pelos grupos.

\section{REFERÊNCIAS}

BNDES, MCTIC BRASIL Produto 8: Relatório do Plano de Ação: Iniciativas e Projetos Mobilizadores, Versão 1.1, 2017

BROWN, T. Design thinking, uma metodologia poderosa para decretar o fim das velhas ideias. São Paulo: Campus, 2010.

BUZAN, T.; BUZAN, B. The mind map book - how to use radiant thinking to maximize your brain's untapped potential. New York: Dutton, 1994.

EPPLER, M. J. A comparison between concept maps, mind maps, conceptual diagrams, and visual metaphors as complementary tools for knowledge construction and sharing. Information Visualization, Vol. 5, No. 3, pp. 202-210, 2006.

EPPLER, M. J. PFISTER, R. A. Comunicação visual - como utilizar o "design thinking” para resolver problemas e se comunicar melhor em qualquer situação. São Paulo: Elsevier, 2014.

MARJANI, M.; NASARUDDIN, F.; GANI, A.; KARIM, A.; HASHEM, A.A.T.; SIDDIQA, A., YAQOOB, I. Big IoT Data Analytics: Architecture, Opportunities, and Open Research Challenges, IEEE Access, Vol. 5, 2017

TSCHIMMEL, K. Design thinking as an effective toolkit for Innovation. In: Proceedings of the XXIII ISPIM Conference: Action for Innovation: Innovating from Experience. Barcelona, 2012.

VIANNA, M.; VIANNA, Y.; ADLER, I. K.; LUCENA, B.; RUSSO, B. Design thinking: inovação em negócios. Rio de Janeiro: MJV Press, 2012.

VIZIOLI, R. Integração da engenharia do valor e do "design thinking" no processo de desenvolvimento de produtos. 2019. Tese (Doutorado em Engenharia Mecânica de Projeto de Fabricação) - Escola Politécnica, Universidade de São Paulo, São Paulo, 2019. Disponível em: <http://www.teses.usp.br/teses/disponiveis/3/3151 /tde-29052019-085110/>. Acesso em: 2019-06.

VIZIOLI, R.; KAMINSKI, P. C. Evolução do "Design Thinking” e suas ferramentas. Em: VIII Congresso Nacional de Engenharia Mecânica, 2014. 